\title{
Young doctors' views on alternative medicine
}

\author{
DAVID TAYLOR REILLY
}

\author{
“. . . what is taken for today's unorthodoxy is \\ probably going to be tomorrow's convention." \\ PRINCE CHARLES, PRESIDENT OF THE BMA.
}

\begin{abstract}
A survey was undertaken to explore attitudes to alternative medicine among 100 general practitioner trainees. A positive attitude emerged from the 86 respondents, with 18 doctors using at least one alternative method themselves and 70 wanting to train in one or more. A total of 31 trainees had referred patients for such treatments; 12 of these doctors made referrals to non-medically qualified practitioners. The most commonly used alternative treatments were hypnosis, manipulation, homoeopathy, and acupuncture. A total of 22 doctors had been treated, or had treated themselves, by an alternative treatment, and this personal experience was linked to a greater professional use.

These findings indicate that alternative methods of treatment are currently being used to complement orthodox medicine and an expansion in their use appears imminent.
\end{abstract}

\section{Introduction}

In recent years increasing numbers of patients have turned to unorthodox practitioners, whose numbers are increasing by around $11 \%$ a year. ${ }^{1}$ This has been the subject of some study ${ }^{1}$ and a lot of media coverage. Apart from some general comments in medical publications, ${ }^{2-4}$ attitudes within the profession are poorly documented. I undertook a study of doctors' attitudes to alternative medical treatments.

\section{Methods}

Questionnaires were distributed at random to 100 general practitioner trainees attending the Scottish national general practitioner trainee conference in June 1982. Eighty seven of the questionnaires were returned, of which 86 were adequately completed. The respondents consisted of 45 men and 37 women and four who did not state their sex. Sixty nine were aged $21-30 ; 12$ were aged $31-40$; two were aged 41-50; and three did not state age.

The questionnaire was designed as part of a patient survey currently in progress, with an additional section added for doctors. The information sought covered the following aspects of alternative medicine:

Lenzie, Glasgow

DAVID TAYLOR REILLY, MRCP, MRCGP, general practitioner trainee

Correspondence to: Glasgow Homoeopathic Hospital, 1000 Great Western Road, Glasgow G12 0NR. knowledge of and attitudes towards alternative treatments; interest in training; present use and referrals, including those to lay practitioners; and personal use.

Perhaps the best definition of an alternative treatment is one that is generally excluded from the medical undergraduate curriculum at any one time. The 15 therapies mentioned in the questionnaire are a fair representation of what is currently topical, from the virtually accepted (hypnosis) through the controversial (faith healing) to the truly esoteric (colour therapy).

The national conference was not on alternative methods but a talk on hypnosis was included and this may have influenced responses on that particular topic.

TABLE I-Knowledge of alternative therapies* among 86 general practitioner trainees. Figures are numbers of doctors

\begin{tabular}{|c|c|c|c|c|}
\hline & $\begin{array}{c}\text { Never } \\
\text { heard of }\end{array}$ & $\begin{array}{l}\text { Heard } \\
\text { of only }\end{array}$ & $\begin{array}{c}\text { Know } \\
\text { something of }\end{array}$ & $\begin{array}{c}\text { Know } \\
\text { a lot }\end{array}$ \\
\hline Hypnosis & & 12 & 64 & 10 \\
\hline Acupuncture & & 18 & 64 & 4 \\
\hline Homoeopathy & & 35 & 49 & 2 \\
\hline Osteopathy & 1 & 45 & 39 & 1 \\
\hline Food allergy & 6 & 45 & 31 & 4 \\
\hline Chiropractic & 15 & 55 & 16 & \\
\hline Herbalism & 8 & 62 & 16 & \\
\hline Megavitamins & 35 & 41 & 7 & 3 \\
\hline Naturopathy & 43 & 39 & 4 & \\
\hline Reflexology & 70 & 15 & 1 & \\
\hline Psionic medicine & 72 & 12 & 2 & \\
\hline Aromatherapy & 77 & 8 & 1 & \\
\hline Colour therapy & 78 & 8 & & \\
\hline Alexander technique & 80 & 2 & 4 & \\
\hline
\end{tabular}

*Faith healing was inadvertently omitted from this section of the questionnaire.

TABLE II-Attitudes of 86 general practitioner trainees to alternative therapies. Figures are numbers of doctors

\begin{tabular}{lccc}
\hline & Useful & Useless & Don't know \\
\hline Acupuncture & 76 & 2 & 8 \\
Hypnosis & 74 & 1 & 11 \\
Homoeopathy & 45 & 3 & 38 \\
Osteopathy & 39 & 5 & 42 \\
Chiropractic & 16 & 6 & 64 \\
Food allergy & 27 & 3 & 44 \\
Faith healing & 27 & 15 & 66 \\
Herbalism & 13 & 7 & 69 \\
Megavitamins & 6 & 11 & 79 \\
Psionic medicine & 1 & 2 & 81 \\
Reflexology & 1 & 6 & 86 \\
Naturopathy & & 5 & 86 \\
Aromatherapy & & & \\
Colour therapy & & & \\
Alexander technique & & &
\end{tabular}

\section{Results}

\section{KNOWLEDGE AND ATTITUDES}

Table I shows the doctors' knowledge of the different therapies. In general, an opinion on the value of a treatment was expressed only if the doctor knew something about it.

A surprisingly positive attitude towards the main therapies emerged (table II), with 76 of the 86 considering acupuncture useful, 74 hypnosis, 45 homoeopathy, and 39 osteopathy. Almost one third 
(27) thought that faith healing was useful, although this also received the highest negative score, with 15 regarding it as useless. The weight of opinion was negative for megavitamin therapy, psionic medicine, reflexology, and naturopathy, though the number expressing negative views here was small.

\section{INTEREST IN TRAINING}

Again the positive response was surprising, with 70 of the 86 respondents wishing to learn at least one method. This figure was similar for both current users of alternative methods $(83 \%$ of 18$)$ and non-users $(81 \%$ of 68$)$. Table III shows the particular interests, with hypnosis a clear first choice. The order of popularity is the same for both current users and non-users, but it is noteworthy that $72 \%$ of all doctors not currently using alternative treatments $(n=68)$ wished to learn hypnosis; corresponding figures for manipulation and acupuncture were $19 \%$, and for homoeopathy $12 \%$.

TABLE III-Details of 70 doctors who wished to train in alternative therapies. Figures are numbers of doctors*

\begin{tabular}{lccc}
\hline & $\begin{array}{c}\text { Current users } \\
(\mathrm{n}=15)\end{array}$ & $\begin{array}{c}\text { Current non-users } \\
(\mathrm{n}=55)\end{array}$ & $\begin{array}{c}\text { Total } \\
(\mathrm{n}=70)\end{array}$ \\
\hline Hypnosis & 11 & 49 & 60 \\
Manipulation & 8 & 13 & $21 \dagger$ \\
Acupuncture & 6 & 13 & 19 \\
Homoeopathy & 2 & 8 & 10 \\
Herbalism & & 1 & 1
\end{tabular}

* Some doctors wished to train in more than one method.

†Three specified osteopathy.

\section{USE OF ALTERNATIVE THERAPIES}

A total of 18 doctors were already treating patients using some of these therapies. Four doctors used more than one method and five failed to give details, so that the following figures are an underestimate. Ten doctors used hypnosis, six used manipulation, two used homoeopathy, and one used acupuncture.

Referrals-More than one third (31) of the doctors had referred patients for treatment by hypnosis, manipulation, homoeopathy, or acupuncture, including three who had referred patients for unspecified treatments. Two thirds of these doctors did not use any of

TABLE IV-Details of conditions for which 31 doctors referred patients for alternative therapies. Figures are numbers of doctors making referrals*

\begin{tabular}{|c|c|c|}
\hline & To another doctor & To a lay practitioner \\
\hline $\begin{array}{l}\text { Hypnosis: } \\
\text { Smoking } \\
\text { Pain } \\
\text { Anxiety/neuroses } \\
\text { Obesity } \\
\text { Psoriasis } \\
\text { Psychosexual } \\
\text { Unstated } \\
\end{array}$ & $\begin{array}{l}6 \\
3 \\
3 \\
2 \\
1 \\
1 \\
1 \\
\end{array}$ & $\begin{array}{l}1 \\
1 \\
1 \\
1\end{array}$ \\
\hline Total & 12 & 4 \\
\hline $\begin{array}{l}\text { Manipulation: } \\
\text { Back pain } \\
\text { Other musculoskeletal disorders } \\
\text { Unstated }\end{array}$ & $\begin{array}{l}7 \\
2 \\
1\end{array}$ & $\begin{array}{l}4 \\
2 \\
1\end{array}$ \\
\hline Total & 10 & 6 \\
\hline $\begin{array}{l}\text { Homoeopathy: } \\
\text { Rheumatoid arthritis } \\
\text { Asthma } \\
\text { Acne } \\
\text { Food allergy } \\
\text { "Various ailments" } \\
\text { Unstated }\end{array}$ & $\begin{array}{l}2 \\
1 \\
1 \\
1 \\
1 \\
4\end{array}$ & 1 \\
\hline Total & 9 & 1 \\
\hline $\begin{array}{l}\text { Acupuncture: } \\
\text { Pain } \\
\text { Smoking } \\
\text { Tenosynovitis } \\
\text { Obesity }\end{array}$ & $\begin{array}{l}4 \\
2 \\
1 \\
1\end{array}$ & 1 \\
\hline Total & 6 & 1 \\
\hline
\end{tabular}
*Some doctors referred patients for more than one type of treatment and three
doctors did not state the therapy used. the methods themselves but referral was more likely $\left(50^{\circ}{ }_{0}\right)$ if the doctor was a user rather than a non-user $\left(32^{\circ}{ }_{0}\right)$. If a doctor wished to train in one of these methods, he was more likely to refer $(38 \%)$ than those uninterested in training $(8 \%)$. Referral for hypnosis was the commonest choice. Twelve doctors had referred patients to a non-medically qualified practitioner, and here manipulation was the most popular therapy (six osteopaths; one chiropractor). In other words, $39 \%$ of referring doctors had referred at some time to lay practitioners. Table IV shows the conditions for which patients were referred. Overall, back pain was the most common condition for which patients were referred, followed by smoking addiction, pain, anxiety/neuroses, and obesity. Patients were referred for homoeopathy, however, with a different set of conditions, and only musculoskeletal disorders were referred for manipulation. It will be noted that some conditions were referred for more than one type of therapy and this may reflect the complementary nature of these treatments.

Personal use-Twenty two of the doctors had themselves been treated by one or other of the alternative therapies, and a further six had seriously considered their use. Ten of them had received treatment from another doctor and eight from a lay practitioner (table V). In other words, almost $10^{\circ} \%$ of the 86 respondents had been treated by a lay practitioner. Interestingly, of the 22 who had received alternative treatment, only two thought that they had not benefited.

It appears that personal experience of alternative methods influenced their professional use. Of the doctors who neither used such therapies nor wished to train in them, none had been treated by any alternative therapy themselves, while more than half of the doctors who both used and wished to train further in these therapies had been treated by one of these methods themselves.

TABLE $\mathrm{v}-$ Details of alternative therapies doctors had received themselves. Figures are numbers of doctors*

\begin{tabular}{lcccc}
\hline & $\begin{array}{c}\text { Treatment by } \\
\text { a doctor } \\
(\mathrm{n}=10)\end{array}$ & $\begin{array}{c}\text { Treatment by a } \\
\text { lay practitioner } \\
(\mathrm{n}=8)\end{array}$ & $\begin{array}{c}\text { Self } \\
\text { treatment } \\
(\mathrm{n}=14)\end{array}$ & $\begin{array}{c}\text { Total } \\
(\mathrm{n}=22)\end{array}$ \\
\hline $\begin{array}{l}\text { Acupuncture } \\
\text { Hypnosis }\end{array}$ & 1 & 1 & 8 & 1 \\
$\begin{array}{l}\text { Homoeopathy } \\
\text { Osteopathy }\end{array}$ & 5 & 2 & 3 & 11 \\
$\begin{array}{l}\text { Chiropractic } \\
\text { Food allergy }\end{array}$ & 1 & 1 & & 1 \\
Faith healing & & 2 & 3 & 2 \\
$\begin{array}{l}\text { Herbalism } \\
\text { Megavitamins }\end{array}$ & 1 & 2 & 1 & 3 \\
Psionic medicine & 2 & & 2 & 3 \\
Yoga & & 1 & 3 & 3 \\
\hline
\end{tabular}

*Some doctors received more than one treatment and from more than one source.

\section{Discussion}

These findings show a striking degree of interest in alternative methods of treatment among younger doctors. About $80 \%$ wished to train in at least one method and about $21 \%$ already used one. Most considered hypnosis, acupuncture, homoeopathy, and manipulation useful and showed an openmindedness about other techniques. Even faith healing is considered-just over half the group expressed an opinion with two to one saying that it was useful, thus rating it more highly than megavitamin treatment. Expressed opinions paralleled knowledge, with few people condemning techniques they knew little about. This is in contrast to the picture frequently painted by the media of narrow minded, drug orientated doctors driving the public to alternative practitioners. What, therefore, might this interest among younger doctors reveal? Is it part of a worrying "flight from science", or a hope for the future?

Certainly to express an interest in the unproved is neither irrational nor unscientific. Advances in medicine are as often founded on the empirical as they are on the theoretical. In other words, the first consideration of science is not "How might something work ?" but merely "Does it work ?" Research and clinical evaluation of these methods is urgently needed to avoid both missed opportunities and false hopes.

It is unlikely that general practitioner trainees are representative of the profession at large. A pilot study has shown much less interest among junior hospital doctors and less still in more senior doctors. Is this a question of the increasing wisdom 
of experience, the inflexibility of age and specialisation, or merely a lack of knowledge? It is noticeable that the positive attitudes in general practitioner trainees are often based on an awareness or personal experience of a treatment-for example, of users who wished to train further in these therapies, more than half had received treatment themselves by an alternative method. The relative lack of interest in junior hospital doctors may reflect the different role of these techniques in the more technological and specialised hospital environment. It may also, however, show something of the different attitudes to medicine in these groups, with the primary care doctor more concerned with "holism."

Though the term "holistic" has been coined to describe the whole person approach of alternative medicine, this is hardly a new idea in orthodox general practice-though current vocational training programmes have found a need to re-emphasise it. Indeed, alternative medicine is in grave danger of committing the orthodox error of overspecialisation, which it claims to reject. Instead of taking your headache to a neurologist, your anxiety to a psychiatrist, and your search for a tonic to the chemist, you now knock on the door of the acupuncturist, hypnotherapist, and health food store in your quest for health. The whole person deserves a whole doctor who can assess his whole problem and who can refer him to a specialist, orthodox or alternative, if required. Based on the data gathered here, it is clear that younger doctors view these methods not as alternative but as complementary to more orthodox approaches.
The interest shown here is not being met in undergraduate curriculums or postgraduate training programmes. It might be argued, however, that doctors should educate themselves in these methods. About 2000 doctors have indeed been trained to some degree by the existing medical associations for hypnosis, acupuncture, manipulation, and homoeopathy, but this contrasts with the number of professional lay practitioners (about 10000 ). Furthermore, if the number not in professional associations is included, there were about 27800 lay practitioners in $1981^{1}$ compared with the total number of general practitioners in Britain in 1982 of 29800 .

It becomes obvious that the exclusion of these methods from medical training carries certain implications for the future.

I wish to thank Morag Taylor, Sheila Gibson, and Rosemary Boyle for their invaluable help.

\section{References \\ ${ }^{1}$ Fulder S, Munro R. The status of complementary medicine in the United Kingdom. London: Threshold Foundation Bureau Limited, 1982: 35-7. (Available from the Institute of Complementary Medicine, 21 Portland Place, London.) \\ ${ }^{2}$ Anonymous. The trial of homoeopathy [Editorial]. Lancet 1983;i:108. \\ ${ }^{3}$ Anonymous. The flight from science [Editorial]. Br Med 7 1980;280:1-2. \\ 4 Tonkin RD. The science and art of healing. Practitioner 1982;226:814-6.}

(Accepted 12 May 1983)

\title{
Learning Medicine
}

\section{Requirements for entry}

\author{
PETER RICHARDS
}

Precise details of the entry requirements for medicine (and all other courses) at each university in the United Kingdom are published annually in the Compendium of University Entrance Requirements for First Degree Courses in the United Kingdom. ${ }^{1}$ The academic standard of most applicants to universities in England, Wales, and Northern Ireland is judged largely on their performance in the General Certificate of Education (GCE) at advanced (A) level. These applicants are all required to get a good grade in chemistry or physical science. Some universities will also consider admission on the strength of results in the full international Baccalaureate including chemistry and in the Scottish Certificate of Education (SCE). Alternatively an honours degree of first or upper second class may be accepted. Otherwise the candidate will have to pass a 1st $\mathrm{MB}$ examination (see below).

Most Scottish applicants to Scottish medical schools and a few who apply outside Scotland are admitted on their results in the Scottish certificate; they are also generally required to study for an additional year after taking the SCE and to pass

St Mary's Hospital Medical School, London W2 1 PG

PETER RICHARDS, MD, FRCP, dean and professor of medicine the Scottish Certificate of Sixth Year Studies, which is taken at the end of that year.

Applicants offering the Scottish certificate outside Scotland should clarify their position with the universities of their choice before completing their UCCA (Universities Central Council for Admissions) applications. London University, for example, requires a good grade in the certificate of sixth year studies as well as the SCE.

With entrance on GCE A level achievement, universities usually require two other science subjects at GCE A level taken from the group of physics (unless physical science is offered), biology, and mathematics. Sometimes a good grade in an arts subject may be accepted in place of one (and occasionally two) other science subjects (see table). Those offering arts subjects are required to have good $\mathrm{O}$ level passes in the sciences or mathematics not offered. O level passes in English language and one other language are also usually expected. Special arrangements may be made for mature students who are not university graduates but these are unlikely to excuse the requirement for chemistry.

Universities do not generally have a preference between A level mathematics and biology for entry to medicine. Nevertheless, more applicants offer biology than mathematics, and however useful it may be to be numerate in medicine, most students who have not taken A level biology find themselves 